\begin{tabular}{|c|c|c|}
\hline Anomanat & & $\mathrm{a} / 4 \mathrm{H}^{2}$ \\
\hline 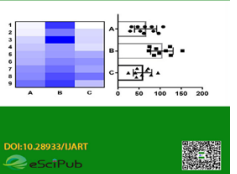 & $\begin{array}{l}\text { International Journal of Addiction Research and Therapy } \\
\qquad(\text { ISSN:2637-8795) }\end{array}$ & 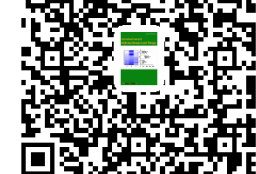 \\
\hline
\end{tabular}

\title{
Prevalence and Perceptions of Cigarettes, Vaping, and Waterpipe Among Veterans
}

\author{
Dana El Hajj, PhD, RN*, Patricia Valverde, PhD, Catherine Battaglia, PhD, RN, Allan V. \\ Prochazka, M.D., M.Sc., Paul. F Cook, PhD \\ University of North Carolina in Wilmington, Rocky Mountain Regional VA Medical Center Aurora, \\ CO
}

\section{ABSTRACT}

Introduction: Vaping has become an epidemic with serious health concerns. The Centers for Disease Control and Prevention recently released a national alert on vaping hazards and its associations with a mysterious lung disease. The prevalence of alternative tobacco products such as waterpipe and vaping have been on the rise, with health hazards similar to those of cigarettes. However, the public is less aware of those hazards. Because the literature on alternative tobacco use among Veterans is limited, the purpose of this study is to examine veterans' use, perceptions, and knowledge of the hazards linked to alternative tobacco products. Materials and Methods: A convenience sample of 200 veterans seeking medical care at the Rocky Mountain Regional VA Medical Center, primary care clinics completed a survey on tobacco use. Results: Cigarettes remain the most prevalent form of tobacco used by veterans. The prevalence of "ever use" of waterpipe and/or vaping was $21 \%$ among participants, and almost all of those participants also reported cigarette use, $20.5 \%$. About $42 \%$ of participants were unaware of harm levels from waterpipe. Discussion: Veterans are unaware of the risks associated with vaping and other alternative tobacco products and show similar use rates as the general population. Because educational campaigns have proven to be successful in decreasing smoking, the next step is to conduct educational campaigns on the hazards of alternative tobacco products among the veteran population to address myths and misperceptions regarding those products.

Keywords: Cigarettes, vape, veterans, waterpipe, alternative tobacco
*Correspondence to Author:

Dana El Hajj, PhD, RN

University of North Carolina in Wilmington, Rocky Mountain Regional VA Medical Center Aurora, CO

How to cite this article:

Dana El Hajj, Patricia Valverde, Catherine Battaglia, Allan V. Prochazka, Paul. F Cook. Prevalence and Perceptions of Cigarettes, Vaping, and Waterpipe Among Veterans. International Journal of Addiction Research and Therapy, 2020, 3:23.

\section{eScîPub}

eSciPub LLC, Houston, TX USA. Website: https://escipub.com/ 
Vaping, a type of alternative tobacco product, has become popular over the past decade and the use of e-cigarettes has been on the rise. ${ }^{1} \mathrm{Re}$ cently the Centers for Disease Control and Prevention (CDC) investigated the association between vaping and lung disease,$^{2}$ referred to as Electronic-cigarette or Vaping Product Use-Associated Lung Injury (EVALI). ${ }^{3}$ Even though the science on the hazards of alternative tobacco products, such as vaping and waterpipe, is not conclusive and still under exploration, current evidence suggests reasons for concern. Moreover, recent research shows that e-cigarettes are associated with a weakened immune system and altered nasal mucosa. ${ }^{4}$ Another study found that the flavoring chemicals in e-cigarettes is associated with impairing neutrophils, macrophages, and natural killer cells. ${ }^{5}$

Although the prevalence of cigarette smoking has decreased over the past several decades, other forms of tobacco use such as vaping and waterpipe are on the rise, ${ }^{7-13}$ with prevalence for either waterpipe or vaping ranging from $14 \%$ to $40 \%$ among the general population over the past decade. ${ }^{14-17}$ Even though tobacco is the most common substance in e-cigarettes, other products such as cannabis are becoming common. ${ }^{19}$ In 2019 the CDC sent out a national alert regarding associations of a mysterious lung disease with vaping, including both vaping with tobacco and THC products. ${ }^{2}$ More recent reports also indicate that vaping may increase the risk of COVID-19 for individuals at any age. ${ }^{3}$ Because the research is not yet conclusive, in this paper the authors are merely making an observation rather than a scientific affirmation regarding ecigarettes and vaping hazards.

Waterpipe use is also gaining popularity among U.S. youth. A 2015 study that examined characteristics and correlates of waterpipe use among young adult U.S. Air Force recruits found a prevalence rate of $28 \%{ }^{20}$ Such a high prevalence rate in waterpipe use among military recruits demonstrates a need to further investigate waterpipe use, characteristics, and associations among veterans. In recent literature, high rates of waterpipe and e-cigarette use have been identified among Air Force recruits. ${ }^{21}$ In addition, more than half of the Air Force trainees in a subsequent study reported using more than one tobacco or nicotine product regularly. ${ }^{22}$ However, estimates of alternative nicotine and tobacco product use, such as cigarettes and vaping, are lacking among the larger veteran population. ${ }^{6}$

Tobacco use among military veterans remains higher than among the non-veteran US population with $21.6 \%$ of veterans reporting current cigarette use and $29.2 \%$ reporting any tobacco product current use. ${ }^{6}$ According to a 2018 Morbidity and Mortality Weekly Report (MMWR) article, any tobacco product use was significantly higher among all veteran groups by age and gender subgroups than their non-veteran counterparts, except males ages $\geq 50$ years. ${ }^{23}$ Within the VA system alone, tobacco-related conditions are estimated to cost approximately $\$ 2.7$ billion. ${ }^{24}$ Results from the 2018 MMWR report reported that $14.0 \%$ of all adults are current cigarette smokers $(15.8 \%$ of men, $12.2 \%$ of women). ${ }^{23}$

However, the literature lacks adequate information on the use of vaping and other alternative tobacco products specifically among veterans. ${ }^{6}$ This is concerning because alternative tobacco products may carry health hazards similar to cigarettes. ${ }^{25-28}$ Those hazards are less known by the public ${ }^{7,28}$ and the majority of people believe alternative tobacco products are safer than cigarettes. Alternative tobacco products are not only advertised as safer than cigarettes but also as a solution to problems with cigarettes, such as bad smell and taste. ${ }^{28}$ Public perceptions that disregard the hazards of alternative tobacco products are largely due to tobacco industry advertisements that glamorize alternative tobacco products to attract adolescents and youth with emotional or sexual appeals. ${ }^{29} \mathrm{E}$-cigarette marketing has corresponded with increased usage of alternative tobacco products. According to reports from the US Department of Health and Human Services, ${ }^{30}$ e-cigarette advertising expenditures grew from $\$ 22.1$ to $\$ 125$ million between 
2012-2014. In 2014, more than 18 million US middle and high school students $(68.9 \%)$ reported being exposed to e-cigarette advertisements through a variety of channels such as retail stores, the internet, TV/movies, newspapers, and magazines. ${ }^{31}$ Because the literature lacks sufficient information about the use of alternative products among veterans despite a concerning rise in usage among the general population, this study aims to evaluate the use of alternative tobacco products and to understand veterans' knowledge and perceptions of those products.

\section{Methods}

\section{Research Design and Data Collection Tool}

We conducted an anonymous survey using screening questions from the CDC Behavioral Risk Factor Surveillance System as a guide for creating the survey questions. The first section of the survey entailed questions about different forms of tobacco use, such as vaping, waterpipe, smokeless tobacco, as well as cigarettes, including "ever use" and "current use." According to the CDC, a current smoker is defined as an adult who has smoked 100 cigarettes in his or her lifetime and who currently smokes cigarettes. This group of current users was divided into "everyday" smokers or "some days" smokers. "Ever use" is defined as someone who has smoked or taken one puff of a cigarette. Knowledge questions about alternative tobacco products were also included in the survey, as were questions to determine how many participants used both traditional and electronic cigarettes and/or waterpipe. Additional questions about marijuana use and alcohol consumption were also part of the survey because such behaviors have been associated with tobacco use..$^{32-33}$ Other questions about demographics and health outcomes such as heart diseases, respiratory diseases, cancer, and mental illness were also included in the survey. The survey questions are included in the appendix.

\section{Study Participants}

The study included two hundred $(N=200)$ veterans seeking are at the Rocky Mountain Regional
VA medical Center in Aurora, Colorado. Inclusion criteria were being a veteran over the age of 18 years old who can read and write English, as the survey was administered in English.

\section{Study Site and Recruitment}

Institutional Review Board approval was obtained prior to any data collected. The VA Rocky Mountain Regional Medical Center, Aurora, Colorado, was used for participant recruitment and data collection. The primary author collected data by doing on-site visits to primary area clinics as well as other waiting areas in the hospital. The primary author approached veterans at the above-mentioned sites and asked potential participants if they would like to participate in the study after explaining the purpose of the study. The survey was administered via paper and pencil. The primary author was present while participants filled the survey in case they needed clarification on some questions. The primary author collected the surveys from participants after survey completion. Data collection occurred between November 2017 and October 2018.

\section{Data Analysis}

SPSS version 24.0 was used for statistical analysis. Descriptive statistics were used to determine the prevalence of all different forms of tobacco use among the sample as well as knowledge towards tobacco use. The chi-square test $\left(\mathrm{X}^{2}\right)$ was used to determine associations between tobacco use and socio-demographics. A $p$-value of .05 was used to determine statistical significance in all analyses.

\section{Results}

A total of 200 veterans completed the survey, with results are shown in Table 1. The sample consisted of mostly male veterans compared to female veterans $(88.1 \%$ vs $10.4 \%, n=176$ vs 21 ) with some college education $(42 \%, n=84)$. The majority of the sample was white $(61 \%, n=$ $122)$ and over the age of 50 years $(68.5 \%, n=$ 137).

\section{Tobacco Use}

Of the respondents, $76 \%(n=152)$ had ever tried cigarettes, $63 \%(n=126)$ were lifetime cigarette 
Dana El Hajj et al., IJART, 2020 3:23

smokers (smoked more than 100 cigarettes in their lifetime), $23.5 \%$ were current daily cigarette smokers, and $12.5 \%$ smoked on some days during the week. Fifteen percent of subjects $(n=30)$ reported ever vaping, and $13 \%(n=26)$ reported ever using waterpipe. Results revealed that $1 \%$ of the respondents were current waterpipe users while $2 \%$ were current vape users. Among those reporting ever using cigarettes, $20.5 \%(n=41)$ reported ever vaping and/or using waterpipe. Among the sample, $2.5 \%(n=5)$ reported both current cigarette and alternative tobacco product use (vaping and/or waterpipe), as shown in Table 2. Of the entire sample, $24.6 \%(n=47)$ were current marijuana users and $51.3 \%(n=102)$ were current alcohol users.

Table 1. Characteristics of Survey respondents $(N=200)$

\begin{tabular}{|c|c|c|}
\hline & Frequency & Percent \\
\hline \multicolumn{3}{|l|}{ Gender } \\
\hline Men & 176 & 88.1 \\
\hline Women & 21 & 10.4 \\
\hline \multicolumn{3}{|l|}{ Age } \\
\hline $18-29$ & 5 & 2.5 \\
\hline $30-49$ & 53 & 26.5 \\
\hline $50-69$ & 104 & 52.0 \\
\hline $70+$ & 33 & 16.5 \\
\hline \multicolumn{3}{|l|}{ Race } \\
\hline White & 122 & 61 \\
\hline Black & 33 & 19.0 \\
\hline Hispanic/Latino & 38 & 19 \\
\hline Asian, Native American/American Indian, Pacific Islander, Other & 45 & 22.5 \\
\hline \multicolumn{3}{|l|}{ Education } \\
\hline High school or less & 48 & 24 \\
\hline Some college & 84 & 42 \\
\hline Bachelors & 43 & 21.5 \\
\hline Graduate & 20 & 10 \\
\hline \multicolumn{3}{|l|}{ Employment } \\
\hline Employed & 89 & 46.4 \\
\hline Unemployed/disability/retired & 103 & 53.7 \\
\hline \multicolumn{3}{|l|}{ Deployment } \\
\hline Deployed & 119 & 62.3 \\
\hline Not deployed & 72 & 37.7 \\
\hline \multicolumn{3}{|l|}{ Co-morbidities } \\
\hline Heart attack disease & 32 & 16 \\
\hline Stroke & 12 & 6.6 \\
\hline Diabetes & 48 & 26.2 \\
\hline COPD & 21 & 11.9 \\
\hline High blood pressure & 96 & 50.5 \\
\hline Acid reflux & 70 & 37.4 \\
\hline Chronic pain & 88 & 47.1 \\
\hline Cancer & 21 & 11.4 \\
\hline Mental health disorders & 69 & 34.5 \\
\hline \multicolumn{3}{|l|}{ Other products } \\
\hline Current alcohol consumption & 102 & 51.3 \\
\hline Current Marijuana use & 47 & 24.6 \\
\hline
\end{tabular}


Table 2. Ever Use and Current Use of Tobacco Products $(N=200)$

\begin{tabular}{|l|c|c|c|c|}
\hline & \multicolumn{2}{|c|}{ Ever use } & \multicolumn{2}{c|}{ Current use } \\
\hline & Frequency & Percent & Frequency & Percent \\
\hline Cigarettes & 152 & 76 & 70 & 35 \\
\hline Smokeless & 53 & 26.5 & 11 & 5.5 \\
\hline Cigars & 84 & 42 & 7 & 3.5 \\
\hline Vaping & 30 & 15 & 4 & 2 \\
\hline Waterpipe & 26 & 13 & 2 & 1 \\
\hline Pipe & 44 & 22 & 5 & 2.5 \\
\hline Other & 7 & 3.5 & 8 & 4 \\
\hline Alternate Forms of Tobacco (vaping, waterpipe) & 42 & 21 & 6 & 3 \\
\hline Use of cigarettes \& alternative tobacco products & 41 & 20.5 & 5 & 2.5 \\
\hline
\end{tabular}

\section{Demographic Associations of Tobacco Use}

Table 3 showed small positive associations between current cigarette use and having some high school education $\left(X^{2}=11.7, p=.02\right)$. A small positive association was also found between ever vaping and being a male $\left(x^{2}=5.05\right.$, $p=.03$ ), and being a young veteran between 1929 years $\left(x^{2}=8.79, p=.03\right)$. The authors also detected small positive associations between ever use of cigarettes and alternative tobacco products and younger (age 18-29) male veterans $\left(X^{2}=13.36, p=.04\right.$ and $\left.X^{2}=7.79, p=.02\right)$.

\section{Knowledge about Alternative Tobacco Prod- ucts}

The study results, shown in Table 4, found that in comparison to cigarettes, $42.5 \%$ of the respondents did not know the level of harm from waterpipe use, while only $6 \%$ of respondents believed that waterpipe use is more harmful that cigarettes. About $40 \%$ of respondents stated that both vaping and waterpipe are very harmful. Approximately $12.5 \%$ of respondents reported that they believe that vaping will help them quit using cigarettes.

\section{Discussion}

This study is one of the first pilot studies conducted among veterans to evaluate the prevalence of different forms of tobacco use and to examine veterans' knowledge and risk perceptions of such products. The study showed that cigarettes remain the most commonly used tobacco product compared to other forms such vaping and waterpipe. Cigarette smokers in this veteran population were older (over 50) and had lower educational levels (some college). This study found that the use of alternative tobacco products was low for current use; however, one in five veterans reported having tried waterpipe and/or vaping. The reported use of traditional cigarettes in addition to other forms of tobacco products $(20.5 \%, n=41)$ among veterans is a health issue that needs to be addressed because combining two or more tobacco products may contribute to additive nicotine intake and increased or additional health hazards.

Our results are similar to other findings in current literature regarding the prevalence of alternative tobacco product use among the general population, particularly among younger age groups. ${ }^{12,34}$ A recent study showed the overall prevalence of adults using both cigarettes and waterpipe was $12.6 \%$ in Colorado. ${ }^{16}$ Veterans are comparable to the general population when it comes to using multiple tobacco products.

In addition to the rise in the use of alternative products, ${ }^{6}$ another concern is the public's perception that such products are safe, ${ }^{28}$ even though the literature has shown that such products have health hazards similar to cigarettes. Previous studies have found that the majority of the population is unaware of the health risks of vaping and other products and perceives them to be a safer and a healthier option to cigarettes. ${ }^{28} \mathrm{An}$ analysis of perceived harms of e-cigarettes by adults in 2012, 2014, and 2015 
reported increasing views of e-cigarette harm regardless of smoking status, with $12.8 \%, 30.9 \%$, and $39.8 \%$ responding that e-cigarettes have equal or greater harm than cigarettes over the three time points, similar to our findings. ${ }^{35} \mathrm{Com}$ pared to people who had never tried cigarettes, adults who have tried e-cigarettes and men in general showed a lower adjusted odds of perceiving e-cigarettes to be equally harmful or more harmful than cigarettes, while adults older than 25 reported higher odds of perceived harm of e-cigarettes. One growing concern is that use of both cigarettes and alternative tobacco products may contribute to negative health outcomes because individuals are being exposed to higher nicotine amounts. ${ }^{36}$

\begin{tabular}{|c|c|c|}
\hline & $N$ & Percentage \\
\hline \multicolumn{3}{|c|}{ Level of harm from cigarettes } \\
\hline Very harmful & 160 & 80.5 \\
\hline Moderately harmful & 15 & 7.5 \\
\hline Little & 1 & 0.5 \\
\hline Not at all & 0 & 0.0 \\
\hline No response & 24 & 12.0 \\
\hline \multicolumn{3}{|c|}{ Level of harm from vaping } \\
\hline Very harmful & 80 & 40.0 \\
\hline Moderately harmful & 39 & 19.5 \\
\hline Little & 23 & 11.5 \\
\hline Not at all & 1 & 0.5 \\
\hline No response & 57 & 28.5 \\
\hline \multicolumn{3}{|c|}{ Level of harm from waterpipe } \\
\hline Very harmful & 85 & 42.5 \\
\hline Moderately harmful & 35 & 17.5 \\
\hline Little & 16 & 8.0 \\
\hline Not at all & 1 & 0.5 \\
\hline No response & 63 & 31.5 \\
\hline \multicolumn{3}{|c|}{ In comparison to cigarettes, waterpipe is: } \\
\hline Less harmful & 11 & 5.5 \\
\hline Similar & 20 & 10.0 \\
\hline More harmful & 12 & 6.0 \\
\hline Don't know & 85 & 42.5 \\
\hline \multicolumn{3}{|c|}{ Does vaping help with quitting? } \\
\hline Yes & 25 & 12.5 \\
\hline No & 50 & 26.0 \\
\hline Do not know & 71 & 35.5 \\
\hline
\end{tabular}

The CDC recently reported more than 400 possible vaping illnesses across 33 states, with health officials urging people not to buy vaping products (CDC, 2019). ${ }^{37}$ The authors hope that this alert will be a wake-up call for individuals to consider the health risk of such products. The more recent pandemic of COVID-19 has affected individuals of all age groups, especially those who are immunocompromised and have preexisting conditions. COVID-19 attacks the lungs, leaving individuals who smoke, vape, or use marijuana at a higher risk or getting worse or not even recover. ${ }^{38}$ Education campaigns have been successful in reducing cigarette use in the United States. There is a critical need for similar educational campaigns that address the 
hazards of alternative products as well as the recent concerns that may be associated with coronavirus among veterans as well as the larger civilian community.

\section{Implications and Future Directions}

This is one of the first projects conducted to determine the prevalence of alternative tobacco products among veterans. The long term future direction of this research will be to conduct educational campaigns not only among veterans but also the general community about the dangers of alternative forms of tobacco in current use. Additionally, providers should be encouraged to include alternative tobacco products in current tobacco screening practices. The researchers recommend that tools be created for an educational awareness campaign to help VA providers facilitate conversations with veterans about their use of non-cigarette tobacco products.

\section{Limitations}

Some limitations need to be considered in interpreting the results of this study. The first limitation was the use of a convenience non-probabilistic sampling method, which limits the generalizability of these results. In addition, the relatively older age and predominance of male participants, as well as the use of a single site for recruitment and data collection were limiting factors that clearly reduce generalizability in the findings. Finally, the survey instrument posed general questions regarding knowledge of alternative tobacco products.

\section{Conclusions}

Cigarette use is still the most prevalent form of tobacco use among veterans, but similar to the general population, use of alternate tobacco products in on the rise. Veterans, like the general population, believe that such products are safer and have lower risks than cigarettes. The research on vaping and waterpipe has shown that such products may have similar health hazards as cigarettes, and recent alerts from the CDC indicate that hazards may be even worse than cigarettes. Scientists are also investigating the risks of heating other chemicals and oils in the vaping products and those long-term health effects. The health risks of alternative products are not completely explored nor conclusive; however, our goal is to conduct educational awareness campaigns addressing the health risks of such products and to disseminate that knowledge to stop the vaping epidemic.

\section{Acknowledgements \\ Declaration of Conflicting Interests}

The authors declare that there is no conflict of interest.

\section{Funding}

The authors received no financial support for the research, authorship, and/or publication of this article.

\section{References}

1. Jenssen, B.P., \& Boykan, R. (2019). Electronic cigarettes and youth in the United States: A call to action (at the local, national and global levels). Children (Basel), 6, E30. https://doi.org/10.3390/children6020030

2. Tanne, J.H. (2019). Don't vape, CDC says, as U.S. lung disease epidemic grows. BMJ: British Medical Journal, 366, 15479. https://doi.org/10.1136/bmj.15479

3. Javelle, E. (2020, April 18). Electronic cigarette and vaping should be discouraged during the new coronavirus SARS-CoV-2 pandemic. Archives of Clinical Toxicology, 94, 2261-2262. https://doi.org/10.1007/s00204-020-02744-z

4. Martin, E. M., Clapp, P. W., \& Rebuli, M. E., Pawlak, E. A., Glista-Baker, E., Benowitz, N. L., Fry, R. C., \& Jaspers, I. (2016). E-cigarette use results in suppression of immune and inflammatory-response genes in nasal epithelial cells similar to cigarette smoke. American Journal of Physiology, 311(1), L135-44. https://doi.org/10.1152/ajplung.00170.2016

5. Hickman, E., Herrera, C.A., \& Jaspers, I. (2019). Common e-cigarette flavoring chemicals impair neutrophil phagocytosis and oxidative burst. Chemical Research in Toxicology, 32(6), 982-85. https://doi.org/10.1021/acs.chemrestox.9b00171

6. Odani, S., Agaku, I. T., Graffunder, C. M., Tynan, M. A., \& Armour, B. S. (2018). Tobacco product use among military veterans-United States, 2010-2015. Morbidity and Mortality Weekly Report, 67(1), 7-12. https://doi.org/10.15585/mmwr.mm6701a2

7. American Lung Association. (2007). An emerging deadly trend: Water pipe tobacco use. 
http://www.lungusa2.org/embargo/slati/Trendalert_Waterpipes.pdf

8. Cobb, C., Ward, K. D., Maziak, W., Shihadeh, A. L., \& Eissenberg, T. (2010). Waterpipe tobacco smoking: An emerging health crisis in the United States. American Journal of Health Behavior, 34(3), 275-285. https://doi.org/10.5993/ajhb.34.3.3

9. Maziak, W. (2011). The global epidemic of waterpipe smoking. Addictive Behaviors, 36(1-2), 1-5. https://doi.org/10.1016/j.addbeh.2010.08.030

10. Maziak, W. (2013). The waterpipe: an emerging global risk for cancer. Cancer Epidemiology, 37(1), 1-4. https://doi.org/10.1016/j.canep.20 12.10.013

11. Schoenborn, C. A., \& Gindi, R. M. (2015). Electronic cigarette use among adults: United States, 2014. National Center for Health Statistics, 2015. (NCHS Data Brief No. 217). https://www.cdc.gov/ hchs/data/databriefs/db217.pdf

12. Centers for Disease Control and Prevention. (2017). Quickstats: Percentage of adults who ever used an e-cigarette and percentage who currently use e-cigarettes, by age group-National Health Interview Survey, United States, 2016. Morbidity and Mortality Weekly Report, 66(33),892. https://doi.org/10.15585/mmwr.mm6633a6

13. National Academies of Sciences, Engineering, and Medicine. (2018). Public health consequences of e-cigarettes. National Academies Press. https://doi.org/10.17226/24952

14. Goodwin, R. D., Grinberg, A., Shapiro, J., Keith, D., McNeil, M. P., Taha, F., Jiang, B., \& Hart, C. L. (2014). Hookah use among college students: prevalence, drug use, and mental health. Drug and Alcohol Dependence, 141, 16-20. https://doi.org/10.1016/j.drugalcdep.2014.04.024

15. Holtzman, A. L., Babinski, D., \& Merlo, L. J. (2013). Knowledge and attitudes toward hookah usage among university students. Journal of American College Health, 61(6), 362-370. https://doi.org/10.1080/07448481.2013.818000

16. Rahman, S., Chang, L., Hadgu, S., Salinas-Miranda, A., \& Corvin, J. (2014). Prevalence, knowledge, and practices of hookah smoking among university students, Florida, 2012. Preventing Chronic Disease, 11, 140099. https://doi.org/10.5888/pcd11.140099

17. El Hajj, .D, Cook, P. F., James, K. A., Battaglia, C., \& Prochazca, A. V. (2019). Newer forms of tobacco products: Characteristics of poly users among adults living in Colorado-a secondary data analysis of the Attitudes and Behaviors Survey on Health 2015. Tobacco Use Insights, 12, $1179173 \times 1974811$.

https://doi.org/10.1177/1179173X19874811
18. Cullen. K. A., Ambrose, B. K., Gentzke, A. S., Apelberg, B. J., Jamal, A., \& King, B. A. (2018). Notes from the field: Increase in use of electronic cigarettes and any tobacco product among middle and high school students - United States, 20112018. Morbidity and Mortality Weekly Report, 67(45), 1276-1277. https://doi.org/10.15585/mm wr.mm6745a5

19. Trivers, K. F., Phillips, E., Gentzke, A. S., Tynan, M. A., \& Neff, L. J. (2018). Prevalence of cannabis use in electronic cigarettes among US youth. JAMA Pediatrics, 172(11), 1097-1099. https://doi.org/10.1001/jamapediatrics.2018.1920

20. Linde. B. D., Ebbert, J. O., Pasker, C. K., Talcott, G., W., Schroeder, D. R., Hanson, A. C., \& Klesges, R. C. (2015). Prevalence and predictors of hookah use in US Air Force military recruits. Addictive Behaviors, 47, 5-10. https://doi.org/10.1016/j.addbeh.2015.03.012

21. Little, M. A., Derefinko, K. J., Colvin, L., Ebbert, J. O., Bursac, Z., Talcott, G. W., Richey, P. A., \& Klesges, R. C.. (2015). The prevalence of e-cigarette use in a sample of US Airforce recruits. American Journal of Preventive Medicine, 49(3), 402-8. https://doi.org/10.1016/j.amepre.2015.02. 019

22. Little, M. A., Bursac, Z., Derefinko, K. J. ,Ebbert, J. O., Talcott, G. W., Hryshko-Mullen, A., \& Klesges, R. C.. (2016). Types of dual and polytobacco users in the U.S. military. American Journal of Epidemiology, 184(3), 21118. https://doi.org/10.1093/aje/kwv321

23. Wang, T. W., Gentzke, A., Sharapova, S., Cullen, K. A., Ambrose, B. K., \& Jamal, A. (2018). Tobacco product use among middle and high school students-United States, 2011-2017. Morbidity and Mortality Weekly Report, 67(22), 629. https://doi.org/10.15585/mmwr.mm6722a3

24. Barnett, P. G., Hamlett-Berry, K., Sung, H. Y., \& Max, W. (2015). Health care expenditures attributable to smoking in military veterans. Nicotine \& Tobacco Research, 17(5), 586-91. https://doi.org/10.1093/ntr/ntu187

25. Akl, E. A., Gaddam, S., Gunukula, S. K., Honeine, R., Jaoude, P. A., \& Irani, J. (2010). The effects of waterpipe tobacco smoking on health outcomes: A systematic review. International Journal of Epidemiology, 39(3), 834-57. https://doi.org/10.1093 /ije/dyq002

26. Aslam, H. M., Saleem, S., German, S., \& Qureshi, W. A. (2014). Harmful effects of shisha: Literature review. International Archives of Medicine and Supplements, 7, 16. https://doi.org/10.1186/17557682-7-16

27. Berry, C., Burton, S., \& Howlett, E. (2017). The impact of e-cigarette addition warnings and 
health-related claims on consumers' risk beliefs and use intentions. Journal of Public Policy Marketing, 36(1), 54-69. https://doi.org/10.1509/ jppm.15.024

28. Kim, M., Popova, L., Halpern-Felsher, B., \& Ling, P. M. (2019). Effects of e- cigarette advertisement on adolescents' perceptions of cigarettes. Health Communication. 34(3), 290-297. https://doi.org/10.1080/10410236.2017.1407230

29. Padon, A. A., Maloney, E. K., \& Cappella, J. N. (2017). Youth-targeted e-cigarette marketing in the U.S. Tobacco Regulatory Science, 3(1), 95101. https://doi.org/10.18001/TRS.3.1.9

30. U. S. Department of Health and Human Services. (2016). E-cigarette use among youth and young adults: A report of the Surgeon General. http://ecigarettes.surgeongen eral.gov/resources.html

31. Singh, T., Marynak, K., Arrazola, R. A., Cox, S., Rolle. I. V., \& King, B. A. (2016). Vital signs: Exposure to electronic cigarette advertising among middle school and high school students-United States, 2014. Morbidity and Mortality Weekly Report, 64(52), 1403-1408. https://doi.org/10. 15585/ mmwr.mm6452a3

32. Hindocha, C., Shaban, N. D. C., Freeman, T. P., Das, R. K., Gale, G., Schafer, G., Falconer, C. J., Morgan, C. J. A., \& Curran, H. V. (2015). Associations between cigarette smoking and cannabis dependence: a longitudinal study of young cannabis users in the United Kingdom. Drug and Alcohol Dependence. 148, 165-171. https://doi.org/10.1 016 /j.drugalcdep.2015.01.004

33. Jiang. N., Lee, Y. O., \& Ling, P. M. (2014). Association between tobacco and alcohol use among young adult bar patrons: a cross-sectional study in three cities. BMC Public Health. 14, 500. https://doi.org/10.1186/1471-2458-14-500

34. Miech, R. A., Johnston, L. D., O'Malley, P. M., Bachman, J. G., Schulenberg, J. E., \& Patrick, M. E. (2018). Monitoring the future: National survey results on drug use, 1975-2017: volume I, secondary school students. Institute for Social Research, University of Michigan,. http://monitoringthefuture.org/pubs.html\#monographs

35. Majeed, B. A., Stanton, C. A., Dube, S. R., Sterling, K. L., Burns, J. D., \& Eriksen, M. P. (2016). Electronic cigarette use among current smokers: a pilot qualitative study. Health Behavior and Policy Review, 3(6), 590-596. https://doi.org/10. 14485/HBPR.3.6.8

36. Goniewicz, M. L., Smith, D. M., Edwards, K. C., Blount, B. C., Caldwell, K. L., Feng, J., Wang, L., Christensen, C., Ambrose, B., Borek, N., Van Bemmel, D., Konkel, K., Erives, G., Stanton, C. A., Lambert, E., Kimmel, H. L., Hatsukami, D., Hecht, S. S., Niaura, R. S., Travers, M., Lawrence C., \&
Hyland, A. J. (2018). Comparison of nicotine and toxicant exposure in users of electronic cigarettes and combustible cigarettes. JAMA Network Open, 1(8):e185937. https://doi.org/10.1001/jamanet workopen.2018.5937

37. Centers for Disease Prevention and Control. (2019). Outbreak of lung injury associated with ecigarette use, or vaping. https://www.cdc.gov/tobacco/basic_information/e-cigarettes/severelung-disease.html

38. Majmundar, A., Allem, J. P., Cruz, T. B., \& Unger, J. B. (2020). Public health concerns and unsubstantiated claims at the intersection of vaping and COVID-19. Nicotine and Tobacco Research, 22(9), 1667-1668. https://doi.org/10.1093/ntr/ntaa 064 